\title{
Extreme flood abatement in large dams with fixed-crest spillways
}

\author{
Alvaro Sordo-Ward ${ }^{\mathrm{a}, *}$, Luis Garrote ${ }^{\mathrm{a}}$, Francisco Martín-Carrasco ${ }^{\mathrm{a}}$, María Dolores Bejarano ${ }^{\mathrm{b}}$
}

\begin{abstract}
S U M M A R Y
This study characterises the abatement effect of large dams with fixed-crest spillways under extreme design flood conditions. In contrast to previous studies using specific hydrographs for flow into the reservoir and simplifications to obtain analytical solutions, an automated tool was designed for calculations based on a Monte Carlo simulation environment, which integrates models that represent the different physical processes in watersheds with areas of $150-2000 \mathrm{~km}^{2}$. The tool was applied to 21 sites that were uniformly distributed throughout continental Spain, with 105 fixed-crest dam configurations. This tool allowed a set of hydrographs to be obtained as an approximation for the hydrological forcing of a dam and the characterisation of the response of the dam to this forcing. For all cases studied, we obtained a strong linear correlation between the peak flow entering the reservoir and the peak flow discharged by the dam, and a simple general procedure was proposed to characterise the peak-flow attenuation behaviour of the reservoir. Additionally, two dimensionless coefficients were defined to relate the variables governing both the generation of the flood and its abatement in the reservoir. Using these coefficients, a model was defined to allow for the estimation of the flood abatement effect of a reservoir based on the available information. This model should be useful in the hydrological design of spillways and the evaluation of the hydrological safety of dams. Finally, the proposed procedure and model were evaluated and representative applications were presented.
\end{abstract}

\section{Introduction}

Reservoirs and dams play a determining role in flood abatement, mitigating the adverse effects downriver from these structures. In addition to placing human lives at risk, dam failure can cause significant material damage. According to statistics from ICOLD (1995), among the $0.5 \%$ of dams constructed after 1950 that have since failed, $36 \%$ of these failures were attributed to hydrological causes. In effect, numerous dam breaks are caused by spillage over the top of the dam due to insufficient drainage mechanisms. The Spanish guidelines for the hydrological safety of dams (SPANCOLD, 1997) set return periods (hereinafter $\mathrm{Tr}$ ) of between 500 and 1000 years for the calculation of design floods and between 5000 and 10,000 years for extreme floods. In countries like Spain where there are more than 1300 large dams, the extremal characterisation of the hydrological behaviour of watersheds and the analysis of dams response is a matter of great importance for many problems related to the planning and homeland security of the area served by a dam in both the design and operational phases (Serrano-Lombillo et al., 2010).

In professional practice, with the development of informatics and hydrometeorological models, the focus of hydrological safety analysis has changed from the treatment of flow volume to rain. In this type of analysis, a "projected design storm" is defined as a storm that gives rise to a "projected design flood", which is used to design dam outlet equipment and therefore allow characterising the hydrological security of the dam. This procedure, which is basically deterministic, introduced a single probabilistic concept corresponding to the probability of the occurrence of a certain amount of accumulated precipitation within a specific period. The remaining physical processes are defined deterministically according to the criteria of the designer, although there is a high degree of uncertainty regarding these processes. Additionally, the same probability of occurrence that is adopted for precipitation is also associated with the "projected design flood", a hypothesis that is not necessarily true (Adams and Howard, 1986; Alfieri et al., 2008; Viglione and Blöschl, 2009).

In contrast to other areas of engineering, on issues related to hydrological design, certain informatical, scientific and methodological advances have not been sufficiently developed for their transfer into professional environments. This is due in large part to the large number of variables involved in each of the processes 
and the stochastic nature of many of these variables. These variables include those related to storm-generation processes (e.g., the volume, duration, intensity, temporal and spatial distribution and recurrence of precipitation), runoff generation (the morphological characteristics of the watershed, the hydraulic characteristics of the soil, the moisture conditions of the soil, air temperature, evapotranspiration, underground flow transportation, etc.), reservoir and dam characteristics (the geometry and volume of the reservoir, the types and geometry of the outlet equipment, etc.) and the variability of the rules of operation of the outlet equipment when faced with a flood (including the flood control volume and the initial level in the reservoir).

Regarding precipitation characterisation, the application of stochastically generated rain has been developed in recent years in field flood simulations and in studies with a probabilistic focus. The Neyman-Scott and Bartlett-Lewis models based on rectangular pulses, which have been applied to the temporal simulation of precipitation at a single site, are the most widely used (Cernesson et al., 1996; Wilks and Wilby, 1999; Srikanthan and McMahon, 2001; Arnaud et al., 2007). These models are capable of performing hourly disaggregation based on daily data with an acceptable degree of adjustment. Several countries have performed rainfall characterisation studies in various locations, including estimating the probability distribution functions of the volume and duration of rain events, of the time between events and of the number of events (see, for example, Adams and Papa, 2000). However, in Spain, this type of analysis has been performed at only a few sites (Rebolé et al., 2009; Barnolas and Llasat, 2007), making it difficult to apply these techniques in a national geographic context. Additionally, in the study of dam flooding, when the studied watershed extends for hundreds or thousands of $\mathrm{km}^{2}$, the average rainfall pattern over the watershed should be represented as composite of various rain-gauge measurements, which also makes this approach difficult. Currently, the continuous space-time stochastic generation of rainfall processes is in a state of development, although good results have already been reported (see, for example, Burton et al., 2008, 2010).

The estimation of the extremal characteristics of the watershed response through the use of rainfall-runoff models, for both event and continuous simulations, is a line of research that has been greatly developed, fundamentally due to informatics advancements. Several authors have estimated, with an acceptable degree of fit, the extremal frequency laws for the maximum inflows into a reservoir (hereinafter $\mathrm{Qi}$ ) in various watersheds (with areas between 1 and $800 \mathrm{~km}^{2}$ ) based on stochastic rain models coupled with the generation of integrated hydrographs in a Monte Carlo procedure (De Michele and Salvadori, 2002; Arnaud and Lavabre, 2002; Loukas, 2002; Rahman et al., 2002; Aronica and Candela, 2007; Samuel and Sivapalan, 2008). Other researchers have estimated these frequency laws by continuous simulation (Cameron et al., 2000; Boughton and Droop, 2003; Blazkova and Beven, 2004,2009 ), although with some limitations due to the intensive demands of the calculations. This calculational complexity is caused by the spatial resolution $(10-100 \mathrm{~m})$ and the temporal resolution (hourly time steps) required to solve the equations in distributed models. Currently, using high-performance computing, it is already possible to perform both short-interval and long-duration simulations with distributed models in large watersheds. Recent studies have implemented distributed models in parallel computing platforms (Blazkova and Beven, 2004, 2009; Cui et al., 2005; Kollet et al., 2010) with encouraging results.

The importance of the abatement effect of a reservoir and the possible behaviour patterns of its inflow and outflow hydrographs has been shown in prior studies by making various simplifying assumptions to allow for an analytical solution of the problem. For example, Hager and Sinniger (1985) analysed reservoir abatement
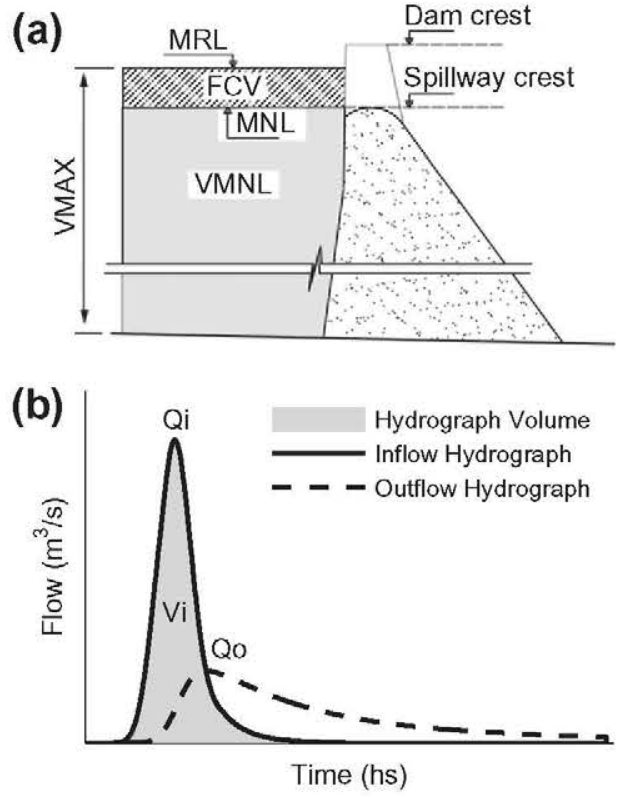

Fig. 1. General schemes for representing notation used: (a) the elevation of the top of the dam, the maximum level the reservoir reaches when a flood occurs Fi (MRL), the maximum volume reached in the reservoir (VMAX), the flood control volume (FCV), the maximum normal level in the reservoir (MNL) and the volume of the reservoir at the MNL elevation (VMNL) and (b) reservoir inflow hydrograph (solid line), where $Q i$ is the peak inflow, the hydrograph of the discharge from the spillway (dashed line), where Qo is the peak outflow, and the volume of the reservoir inflow hydrograph (Vi, shaded area).

based on an inflow hydrograph with a single peak represented by an analytical expression, Horn (1987) and Akan (1989) based an inflow hydrograph for a reservoir on the dimensionless unit hydrograph developed by the U.S. Soil Conservation Service, and Graber (2009) and Hong (2008) analysed triangular, trapezoidal and rectangular inflow hydrographs. Furthermore, the abatement effects of reservoirs have been studied using probabilistic analytical approaches (Rodríguez-Iturbe and Valdés, 1979; Guo, 2001; Quader and Guo, 2006), numerical solutions (Graber, 2009) and laboratory studies (Hong, 2008). In all cases, a simplified schematisation is performed for the storms and watersheds; as a result, these models are most applicable to urban hydrology and small watersheds. In this context, we generated a large set of hydrographs for medium-sized watersheds to represent the stochastic hydrological forcing of large dams, avoiding simplifying assumptions and broadening their range of application with respect to the preceding studies.

The increase in calculational capacity allows for the design of simulation procedures based on the Monte Carlo method that reproduce the behaviour of a system over the course of many thousands of years. In this study, the flood abatement effects of large dams with fixed-crest (FC) spillways were calculated for the occurrence of representative extreme events (with $\mathrm{Tr}$ varying between 500 and 10,000 years) and applied to a wide range of watersheds (with areas varying between 150 and $2000 \mathrm{~km}^{2}$ ) with a probabilistic focus. The specific objectives of the present study were: (a) to define coefficients that relate the variables influencing both the generation of a flood and its abatement in the reservoir and identify homogeneous behaviours in the universe of studied cases, (b) to propose a procedure to evaluate the peak attenuation effect and which allows the reduction of the simulation efforts, and (c) to propose a simple general model which allows for the estimation of the abatement effect of reservoirs and dams with FC spillways based on the available information, and which should be useful in the hydrological design of spillways and the evaluation of dam hydrological safety. 


\section{Notation used}

\begin{tabular}{|c|c|}
\hline AC & $\begin{array}{l}\text { Attenuation Coefficient, defined as the slope of } \\
\text { the linear fit of Qi vs. Qo in each configuration }\end{array}$ \\
\hline adj_FM & $\begin{array}{l}\text { linear model establishing a relationship between } \\
\text { Qi and Qo, based on the calculation of } 10,000 \\
\text { simulations }\end{array}$ \\
\hline ARMA & autoregressive moving average model \\
\hline$F 1$ & a design flood corresponding to $\operatorname{Tr} \approx 500$ years \\
\hline$F 2$ & a design flood corresponding to $\operatorname{Tr} \approx 1000$ years \\
\hline$F 3$ & $\begin{array}{l}\text { an extreme flood corresponding to } \\
\operatorname{Tr} \approx 5000 \text { years }\end{array}$ \\
\hline F4 & $\begin{array}{l}\text { an extreme flood corresponding to } \\
\operatorname{Tr} \approx 10,000 \text { years }\end{array}$ \\
\hline FCV & $\begin{array}{l}\text { flood control volume, defined as the difference } \\
\text { between VMAX and VMNL ( } \mathrm{h} \mathrm{m}^{3} \text { ) (Fig. 1a) }\end{array}$ \\
\hline FC & fixed-crest (spillway) \\
\hline FM & $\begin{array}{l}\text { complete flood abatement model (uses the } \\
\text { Storage Indication Method (SCS, 1972) }\end{array}$ \\
\hline MBLM & modified Bartlett-Lewis Model \\
\hline MNL & $\begin{array}{l}\text { maximum normal level; the maximum level } \\
\text { allowed in the reservoir under normal operation } \\
\text { conditions (m) (Fig. 1a) }\end{array}$ \\
\hline MRL & $\begin{array}{l}\text { maximum level the reservoir reaches when faced } \\
\text { with a flood Fi (m) (Fig. 1a) }\end{array}$ \\
\hline Qi & $\begin{array}{l}\text { the maximum inflow of a reservoir }\left(\mathrm{m}^{3} / \mathrm{s}\right) \\
\text { (Fig. 1b) }\end{array}$ \\
\hline Qo & $\begin{array}{l}\text { the maximum flow discharged by the } \operatorname{dam}\left(\mathrm{m}^{3} / \mathrm{s}\right) \\
\text { (Fig. 1b) }\end{array}$ \\
\hline Qy & $\begin{array}{l}\text { the ratio between the intersection of the fitted } \\
\text { line of Qo vs. Qi with the } y \text {-axis and the } \\
\text { maximum Qo among all the simulations for each } \\
\text { reservoir and dam configuration (dimensionless) }\end{array}$ \\
\hline Qo_SM & $\begin{array}{l}\text { calculated Qo based on a linear fit of Qo vs. Qi for } \\
6 \text { floods }\left(\mathrm{m}^{3} / \mathrm{s}\right)\end{array}$ \\
\hline Qo_SM2 & calculated Qo based on Eq. (5) $\left(\mathrm{m}^{3} / \mathrm{s}\right)$ \\
\hline Qo_FM & $\begin{array}{l}\text { calculated Qo for the flood abatement according } \\
\text { to a full model }(\mathrm{FM})\left(\mathrm{m}^{3} / \mathrm{s}\right)\end{array}$ \\
\hline Qo_adj_FM & $\begin{array}{l}\text { calculated Qo based on a linear fit of Qo vs. Qi for } \\
10,000 \text { floods }\left(\mathrm{m}^{3} / \mathrm{s}\right)\end{array}$ \\
\hline RRC & $\begin{array}{l}\text { reservoir Routing Coefficient, the ratio between } \\
\text { the FCV and the Vi }\end{array}$ \\
\hline SM & $\begin{array}{l}\text { proposed linear model establishing a } \\
\text { relationship between Qi and Qo }\end{array}$ \\
\hline SPANCOLD & Spanish National Committee on Large Dams \\
\hline Vc & Vi corresponding to a $\operatorname{Tr}$ of 1000 years $\left(\mathrm{h} \mathrm{m}^{3}\right)$ \\
\hline $\mathrm{Vi}$ & $\begin{array}{l}\text { volume of the reservoir inflow hydrograph } \\
\left(\mathrm{h} \mathrm{m}^{3}\right) \text { (Fig. 1b) }\end{array}$ \\
\hline VMAX & $\begin{array}{l}\text { maximum volume that is reached in the } \\
\text { reservoir }\left(\mathrm{h} \mathrm{m}^{3}\right) \text { (Fig. 1a) }\end{array}$ \\
\hline $\begin{array}{l}\text { VMNL } \\
\text { tc }\end{array}$ & $\begin{array}{l}\text { volume in the reservoir at } \mathrm{MNL}\left(\mathrm{h} \mathrm{m}^{3}\right) \text { (Fig. 1a) } \\
\text { concentration time }(\mathrm{h})\end{array}$ \\
\hline $\operatorname{Tr}$ & return period (year) \\
\hline
\end{tabular}

\section{Methodology}

The study approach involved the design of a Monte Carlo simulation model. We used a scenario generator based on a chain of aggregated and integrated models to construct a hydrometeorological model. A stochastic storm generator was developed and applied to a hydrological model to obtain a representative sample of inflow hydrographs into the reservoir and the corresponding discharge hydrographs out of the dam. With the goal of providing generality in the results, this procedure was applied to 21 sites (watershed/reservoir/dam systems) in continental Spain and 105 reservoir and dam configurations with FC spillways. Subsequently, behaviour standards were established for the universe of case studies using coefficients that relate the characteristics of the hydrological forcing with those of the reservoirs and spillways. A general procedure was proposed along with a model for estimating the flood abatement effects of reservoirs with FC spillways during extreme flood events (Fig. 2). For a realistic representation of the temporal structure of the rain events and the hydrological response of the watersheds, we selected an hourly time step. It is worth noting the general nature of the study, in which the overall goal of the hydrometeorological model was the generation of a wide and diverse range of feasible hydrographs, and whose results were independent from the hydrological forcing. Additionally, the models and procedures used were recommended by the SPANCOLD (1997) and are those often applied in the Spanish professional practise. In the following, we explain this methodology in detail.

\subsection{Generation of precipitation events}

We designed a Monte Carlo procedure beginning with the stochastic generation of rain episodes (Fig. 3). Given that this study is centred on design and extreme floods (for $\mathrm{Tr}$ between 500 and 10,000 years), obtaining representative samples for the upper range implies, a priori, the execution of approximately 100,000 200,000 simulations (Loukas, 2002; Blazkova and Beven, 2004), which requires a high computational capacity (Bocchiola and Rosso, 2009). To obtain a good representation of the upper branch of a frequency curve for Qi based on a rather low number of simulations while keeping calculation times manageable, synthetic rains were considered with a probability of occurrence $(p)$ less than or equal to 0.02 (where $p=1 / \operatorname{Tr}$, equivalent to $\operatorname{Tr} \geqslant 50$ years). For each dam configuration and storm duration selected, a random sample of $10,000 p$ values was generated (with a random selection of one storm per year) based on a uniform $p$ distribution $(0<p \leqslant 0.02)$, assuring $\operatorname{Tr}$ values in an approximate range between 50 and 500,000 years (Fig. 3). For each element in the sample, we generated a precipitation event by estimating both the total volume of a storm of duration $\mathrm{D}$ associated to its probability of occurrence and its temporal distribution. The total storm volume was calculated in two stages. First, the maximum daily precipitation (for the $\operatorname{Tr}$ considered) was estimated according to an extremal distribution, SQRT-ET $\max$ (Etoh et al., 1986; Zorraquino, 2004) and varying the two parameters $\alpha$ (scale factor) and $K$ (frequency factor) in each location, following recommendations by Ministerio de Fomento (1999) (Spanish Ministry of Public Works) (Fig. 3). In such study, 1545 rainfall stations were selected in the continental Spain with over 30 years of daily records. A statistical modelling of the maximum daily rainfall annual series was performed by estimating regional parameters and quantiles according to four extremal distribution functions: Generalised Extreme Values (GEVs), Log-Pearson III (LP3), Two Components Extreme Values (TCEVs) and SQRT-ET $\max$, the latter being the best fit by the following equation:

$F(x)=e^{\left[-K(1+\sqrt{\alpha x}) e^{(-\sqrt{\alpha x})}\right]}$

where $F(x)$ is the distribution function, $\alpha$ and $K$ the fitted parameters in each location.

Second, different storm durations were analysed (i.e., 0.5, 1, 1.5, 2,3 and 4 of the watershed concentration time (tc)) assuring the inclusion of those which generate the highest $\mathrm{Qi}$ for the $\operatorname{Tr}$ considered (Fig. 3). The total rain volume for the durations was estimated applying the intensity-duration-frequency curves (IDF) proposed 


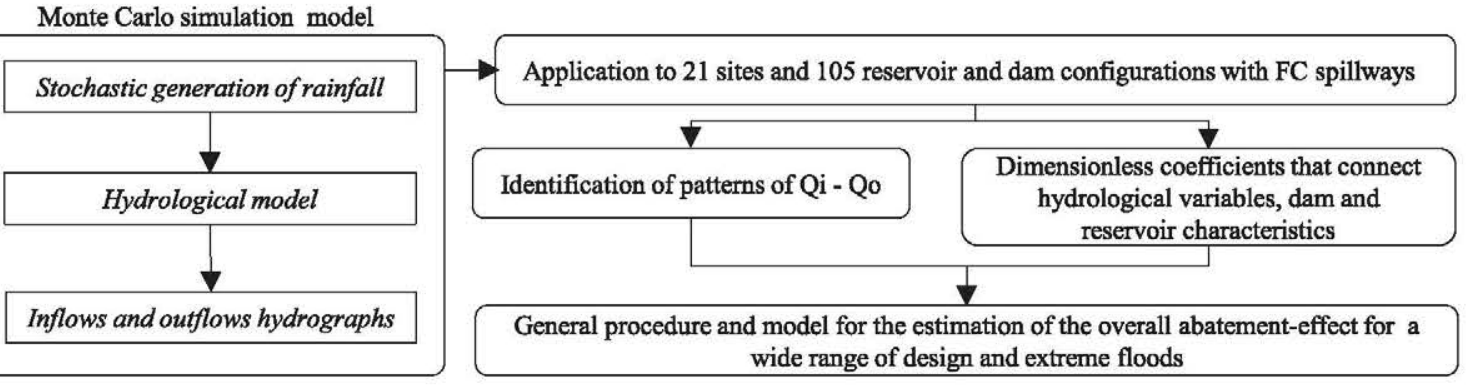

Fig. 2. General conceptual framework of the methodology proposed.

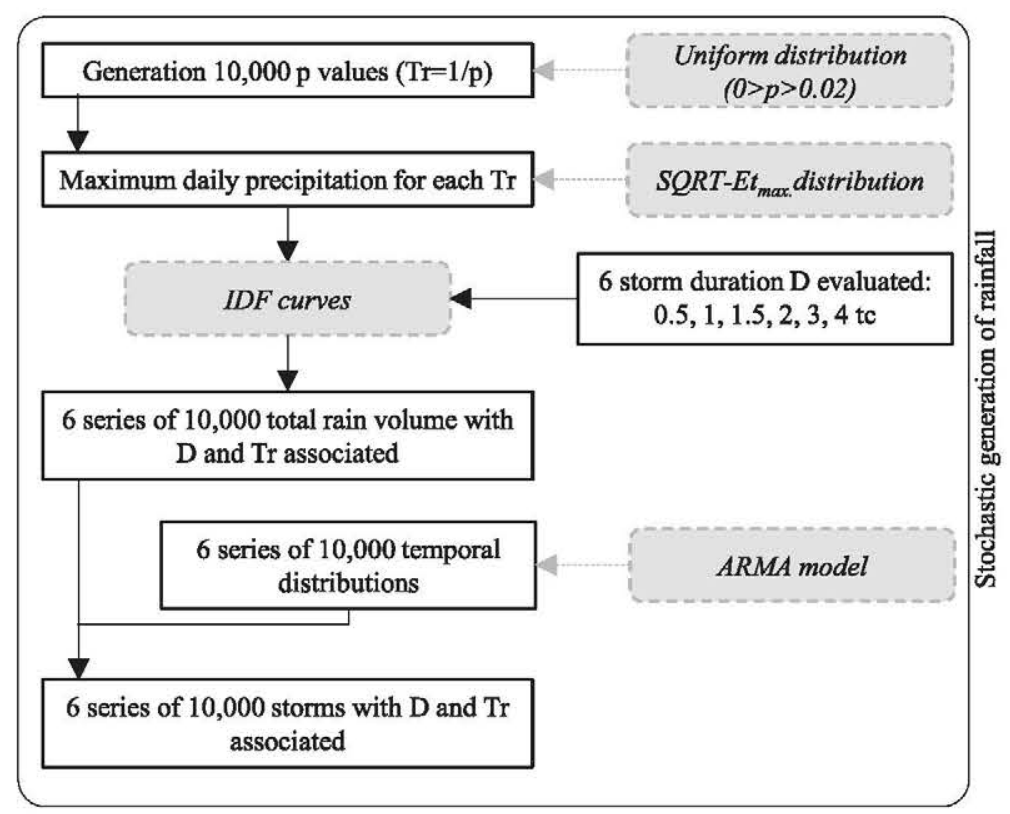

Fig. 3. Flow chart illustrating the steps for the stochastic generation of rainfall. White and solid lines boxes represent the steps performed, grey and dashed boxes indicate the tools used in each step. All processes were integrated in a Monte Carlo framework.

by the Spanish Ministry of Public Works (MOPU, 1990) and recommended by the Spanish National Committee on Large Dams (SPANCOLD, 1997) (Fig. 3):

$\frac{I_{t}}{I_{d}}=\left(\frac{I_{1}}{I_{d}}\right)^{\frac{28^{0.1}-t^{0.1}}{28^{0.1}-1}}$

where $I_{d}$ is the mean intensity of the maximum daily rainfall ( $\mathrm{mm} /$ $\mathrm{h}), I_{1}$ is the hourly rainfall intensity for a given $\operatorname{Tr}(\mathrm{mm} / \mathrm{h}), t$ is the storm duration (h) and $I_{t}$ is the mean intensity in the $t$ period $(\mathrm{mm} / \mathrm{h})$.

For the estimation of the temporal distribution of each rainstorm, we assumed that the generated events were uncorrelated and random for each watershed. The temporal distribution of each event was determined with an autoregressive moving average (ARMA) $(2,2)$ stochastic model (Fig. 3 ). The selection of the model and its orders ( $p$ and $q$ ) were based on the analysis of the rain data available for Spain (source: Automatic System of Hydrological Information; $\mathrm{SAIH}$ ) and results found in the literature (Bras and Rodríguez-Iturbe, 1993; Toth et al., 2000; Bocchiola and Rosso, 2006; Salas and Fernández, 2007). By applying the procedure above described for each site and configuration analysed, we generated six series (one for each storm duration) of 10,000 storm events each (Fig. 3 ).

\subsection{Generation of inflow and outflow hydrographs in the reservoir}

For the generation of the inflow hydrographs in each reservoir, we developed an event-based hydrological model (Fig. 4). A chain of models was constructed to simulate the main physical processes involved: (a) rainfall-runoff transformation, (b) generation of hydrographs, and (c) propagation throughout the stream channels. For the rainfall-runoff transformation we applied the Curve Number method (SCS, 1972; curve numbers provided by CEDEX - the Public Works Studies and Experimentation Centre, Ministry of Development, Spain). The generation of hydrographs was conducted using the Soil Conservation Service dimensionless unit hydrograph procedure (SCSDHU; SCS, 1972). The tc was estimated using the formula proposed by MOPU (1990) and recommended by the SPANCOLD (1997):

$t_{c}=\left(\frac{L}{S^{0.25}}\right)^{0.76}$

where $t_{c}$ is the concentration time (h), $L$ is the length of main channel $(\mathrm{km})$ and $S$ is the slope of the main channel (dimensionless). For the propagation of the flood hydrographs throughout the stream channels we utilised the Muskingum method. For each site and configuration analysed we generated six series of 10,000 inflow hydrographs (Fig. 4). We assigned a probability of occurrence to 


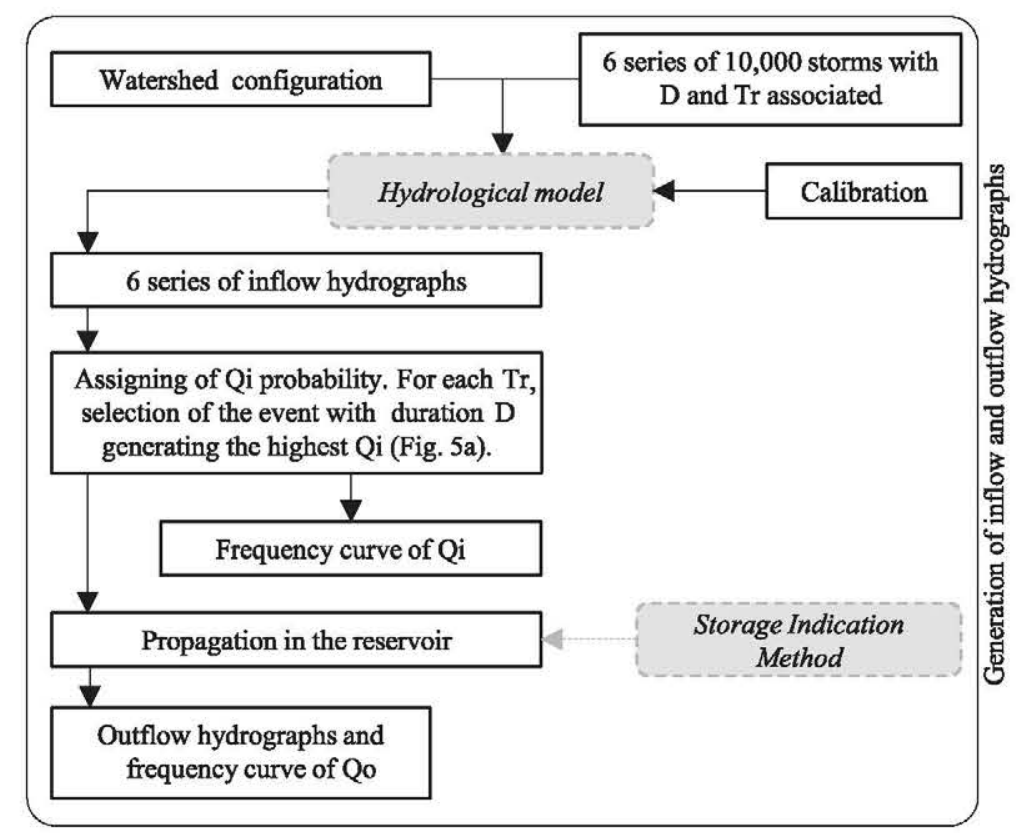

Fig. 4. Flow chart illustrating the steps for the generation of inflow and outflow hydrographs. White and solid lines boxes represent the steps performed, grey and dashed boxes indicate the tools used in each step. All processes were integrated in a Monte Carlo framework.
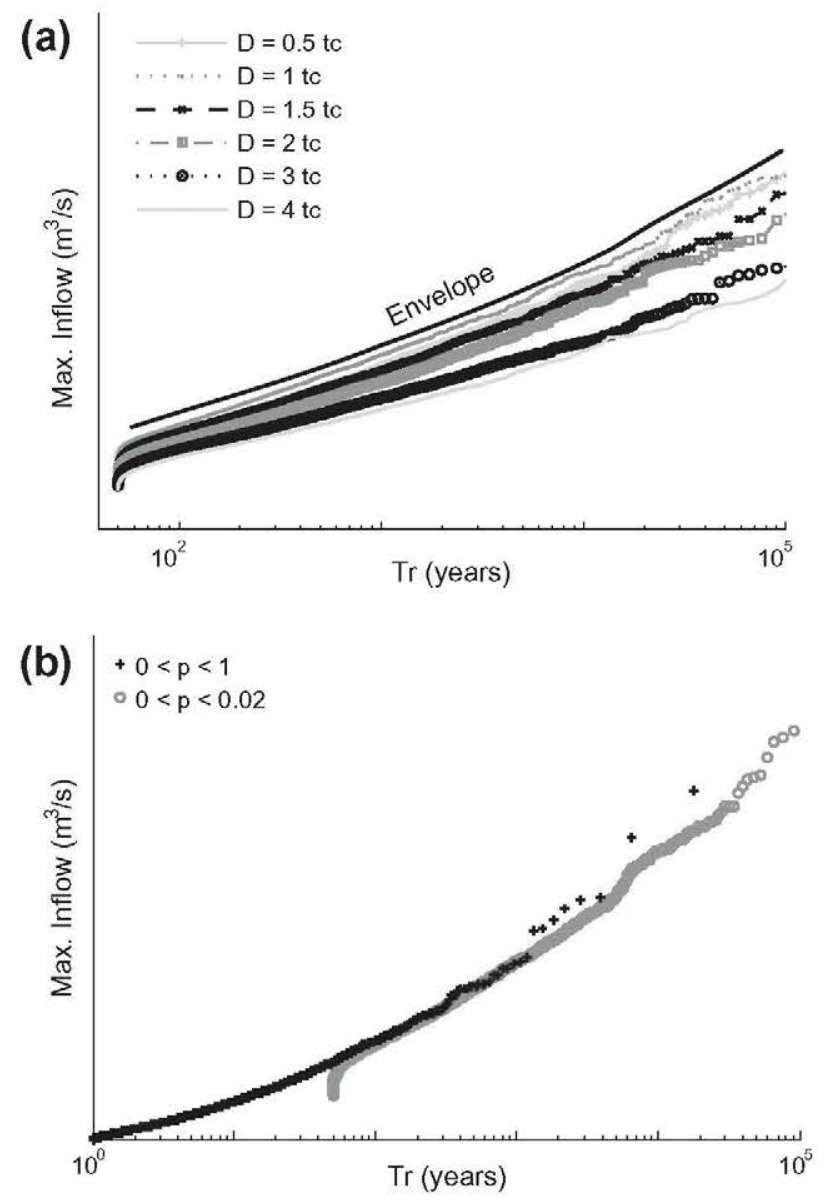

Fig. 5. General schemes representing: (a) frequency curves for Qi for storm events of different durations and the selection of the envelope curve for extremal behaviour and (b) the fit of the frequency curves for Qi obtained from a series of 10,000 simulations with $0<p \leqslant 1$ (crosses) and another with $0<p \leqslant 0.02$ (circles). the Qi generated by each storm event (by applying the Weibull non-parametric formula to $\mathrm{Qi}$ values), and each year a single storm whose duration generates the highest $\mathrm{Qi}$ in that year was selected. Therefore, the upper branch of the frequency law of Qi $(\mathrm{Tr} \geqslant 100$ years) used in this study involves the frequency curves calculated for each level of storm duration (Figs. 4 and $5 a$ ). The procedure shown in Fig. $5 \mathrm{~b}$ can be used to obtain the frequency curve for the entire $\operatorname{Tr}$ range by combining two series of 10,000 events each whose $p$ values range between 0 and 1 and between 0 and 0.02 , respectively. In this study we used the upper branch of the frequency curves and did not require completing the rest of the distributions since we were focused on extreme events.

Models for the generation of inflow hydrographs for the reservoirs were calibrated by adjusting, in each site, the modelled frequency curve for $\mathrm{Qi}$ to match the curve based on measured data (source: CEDEX, 2011). In such study, over 500 gauging stations and reservoirs were selected and their frequency curves for Qi were calculated. Using hydrometeorological and statistical models, distributed values of Qi for different Tr were calculated in the continental Spain. The curve number was the main parameter used for calibration. To validate the proposed procedure for the generation of floods the sensitivity and stability of the results were analysed. The analysis was performed according to the procedure proposed by Loukas (2002) for the case of the Alloz dam (lat.: $\mathrm{N} 42^{\circ} 42^{\prime} 20^{\prime \prime}$, long.: W 1 ${ }^{\circ} 56^{\prime} 36^{\prime \prime}$, located in the watershed of the Duero River, Navarra Province, with a watershed area of $155 \mathrm{~km}^{2}$ and a tc of $6.4 \mathrm{~h}$ ). To verify the stability of the results, 10,000 events were each simulated five times, and the corresponding frequency curves for Qi were determined along with the reservoir inflow hydrograph (Vi) for storms lasting $24 \mathrm{~h}$. The frequency curves were compared for Trs of $100,1000,5000,7000$ and 10,000 years. To analyse the sensitivity of the results to the size of the sample, simulations of $1000,2000,5000,7000$ and 10,000 events were performed.

The propagation of the flood hydrographs in the reservoir was simulated by applying the Storage Indication Method (SCS, 1972; Chow et al., 1988; Ponce, 1989; Fig. 4). The level in the reservoir at the beginning of the rain event was noted and this was taken as the threshold level of the spillway (i.e., the maximum normal level; MNL), and during the occurrence of the flood, the bottom and 


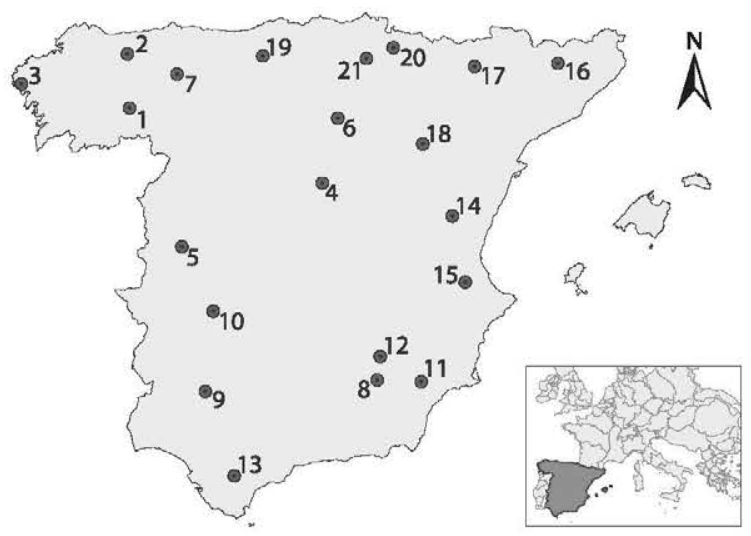

Fig. 6. Locations of the 21 study sites.

intermediate outlet equipment was shut off. Finally, for each site and configuration analysed, a probability of occurrence to the Qo generated by each flood hydrograph (by applying the Weibull non-parametric formula to Qo values) was assigned, and the frequency law for Qo was estimated (Fig. 4).

\subsection{Experimental setup}

Twenty-one study sites were analysed (Fig. 6 and Table 1). At each site, the existing configuration of the reservoir and dam were considered, and alternative configurations were created by varying the length of the FC spillway and the volume of the maximum normal level (VMNL) of the reservoir or, equivalently, the placement of the spillway at different elevations. With respect to the design of spillway configurations different from the existing one, design criteria were established according to Spanish law and the recommendations of the SPANCOLD (1997). Various VMNL situations were analysed for each spillway configuration based on the ratio between the reservoir capacity at MNL and the volume of the inflow hydrograph for a $\operatorname{Tr}$ of 1000 years (Vc) according to the following criteria: (a) the VMNL of the existing configuration and (b) at least two of the following cases were selected as a function of the previous case: a VMNL between 0.1 and $0.25 \mathrm{Vc}, \mathrm{VMNL} \approx 1$ Vc and a VMNL between 2 and $4 \mathrm{Vc}$. With these criteria, 105 reservoir and FC spillway configurations were defined; 93 were used to develop the procedures and models, and 12 were used for model validation in a numerical experiment with more than $6,000,000$ simulations $(10,000$ simulations $\times 6$ storm durations $\times 105$ reservoir and dam configurations). Data were provided by: CEDEX (watershed, rainfall and flow information) and Spanish Basin Authorities (reservoir and dam characteristics).

The flood abatement capacity of each reservoir was evaluated using the ratio between the $\mathrm{Qi}$ and the peak discharge outflow (Qo); see Fig. 1b. Two dimensionless coefficients were proposed to explain the relationships among the main hydrological variables of the reservoir and dam system: (1) the Attenuation Coefficient (AC), defined as the slope of the line resulting from a linear fit of Qi vs. Qo for each configuration (fitted at 10,000 simulations) and (2) the Reservoir Routing Coefficient (RRC), which represents the relationship between $\mathrm{Vi}$ and the maximum abatement volume (FCV, defined as the difference between the maximum volume stored in the reservoir, VMAX, and the VMNL; see Fig. 1a and b), as given by the following equation:

$\mathrm{RRC}=\frac{\mathrm{VMAX}-\mathrm{VMNL}}{\mathrm{Vi}}$

Theoretically, a linear fit of Qi vs. Qo should pass through the coordinate origin because when $\mathrm{Qi}$ is 0 , with the initial condition taken as the level of the reservoir at the elevation of the spillway threshold, Qo is 0 . To verify this condition for each configuration, a dimensionless value, Qy, was defined as the ratio of the $y$-intercept of the fitted Qi vs. Qo line and the maximum Qo.

Subsequently, the behaviour of the RRC was analysed for flood events of different magnitudes usually used for hydrological design (or the evaluation of the safety of existing dams). Characteristic floods were defined (Fi) with different Trs for each Qi: F1 corresponding to $\operatorname{Tr} \approx 500$ years; $F 2$, with $\operatorname{Tr} \approx 1000$ years; $F 3$, with $\operatorname{Tr} \approx 5000$ years; and $F 4$, with $\operatorname{Tr} \approx 10,000$ years. The relationship among the RRC and AC coefficients was studied, and the average observed behaviour was represented by an analytical expression

Table 1

Main characteristics of the study sites and the configurations of the existing reservoirs and dams (MARM, 2011).

\begin{tabular}{|c|c|c|c|c|c|c|c|}
\hline $\begin{array}{l}\text { Basin } \\
\text { ID }\end{array}$ & $\begin{array}{l}\text { Geographic } \\
\text { region }\end{array}$ & $\begin{array}{l}\text { Reservoir } \\
\text { name }\end{array}$ & $\begin{array}{l}\text { Watershed area } \\
\left(\mathrm{km}^{2}\right)\end{array}$ & $\begin{array}{l}\text { Concentration time } \\
\text { (h) }\end{array}$ & $\begin{array}{l}\text { Reservoir volume } \\
\left(\mathrm{h} \mathrm{m}^{3}\right)\end{array}$ & $\begin{array}{l}\text { Dam spillway capacity } \\
\left(\mathrm{m}^{3} / \mathrm{s}\right)\end{array}$ & $\begin{array}{l}\text { Annual runoff }\left(\mathrm{h} \mathrm{m}^{3}\right) \\
\text { year) }\end{array}$ \\
\hline 1 & Cantabrian & Casoyo & 150 & 6.6 & 0.3 & 330 & 55 \\
\hline 2 & Cantabrian & Salime & 1806 & 23.9 & 266 & 2000 & 1558 \\
\hline 3 & Cantabrian & Santa Eugenia & 500 & 19.9 & 18 & 530 & 500 \\
\hline 4 & North Atlantic & Beleña & 475 & 16.8 & 53 & 122 & 160 \\
\hline 5 & North Atlantic & $\begin{array}{l}\text { Gabriel y } \\
\text { Galán }\end{array}$ & 1850 & 25.2 & 910 & 2200 & 1000 \\
\hline 6 & North Atlantic & $\begin{array}{l}\text { Cuerda del } \\
\text { Pozo }\end{array}$ & 550 & 14.0 & 249 & 1473 & 240 \\
\hline 7 & North Atlantic & $\begin{array}{l}\text { Barrios de } \\
\text { Luna }\end{array}$ & 488 & 13.1 & 308 & 1398 & 467 \\
\hline 8 & South Atlantic & San Clemente & 158 & 7.0 & 120 & 620 & 32 \\
\hline 9 & South Atlantic & El Pintado & 1100 & 19.2 & 213 & 1367 & 145 \\
\hline 10 & South Atlantic & Sierra Brava & 210 & 8.6 & 232 & 140 & 51 \\
\hline 11 & Mediterranean & Puentes & 1388 & 19.7 & 26 & 937 & 27 \\
\hline 12 & Mediterranean & Anchuricas & 187 & 10.2 & 6.3 & 823 & 38 \\
\hline 13 & Mediterranean & Los Hurones & 288 & 7.9 & 135 & 917 & 134 \\
\hline 14 & Mediterranean & Los Toranes & 996 & 18.1 & 0.5 & 374 & 199 \\
\hline 15 & Mediterranean & Escalona & 507 & 12.0 & 461 & 1186 & 59 \\
\hline 16 & Pyrenean & La Baells & 507 & 10.6 & 365 & 740 & 211 \\
\hline 17 & Pyrenean & Mediano & 2078 & 19.7 & 435 & 3481 & 1288 \\
\hline 18 & Pyrenean & Las Torcas & 456 & 19.3 & 6.7 & 240 & 30 \\
\hline 19 & Pyrenean & Ebro & 466 & 11.5 & 540 & 560 & 300 \\
\hline 20 & Pyrenean & Itoiz & 485 & 14.7 & 418 & 574 & 675 \\
\hline 21 & Pyrenean & Alloz & 155 & 6.4 & 65 & 247 & 120 \\
\hline
\end{tabular}



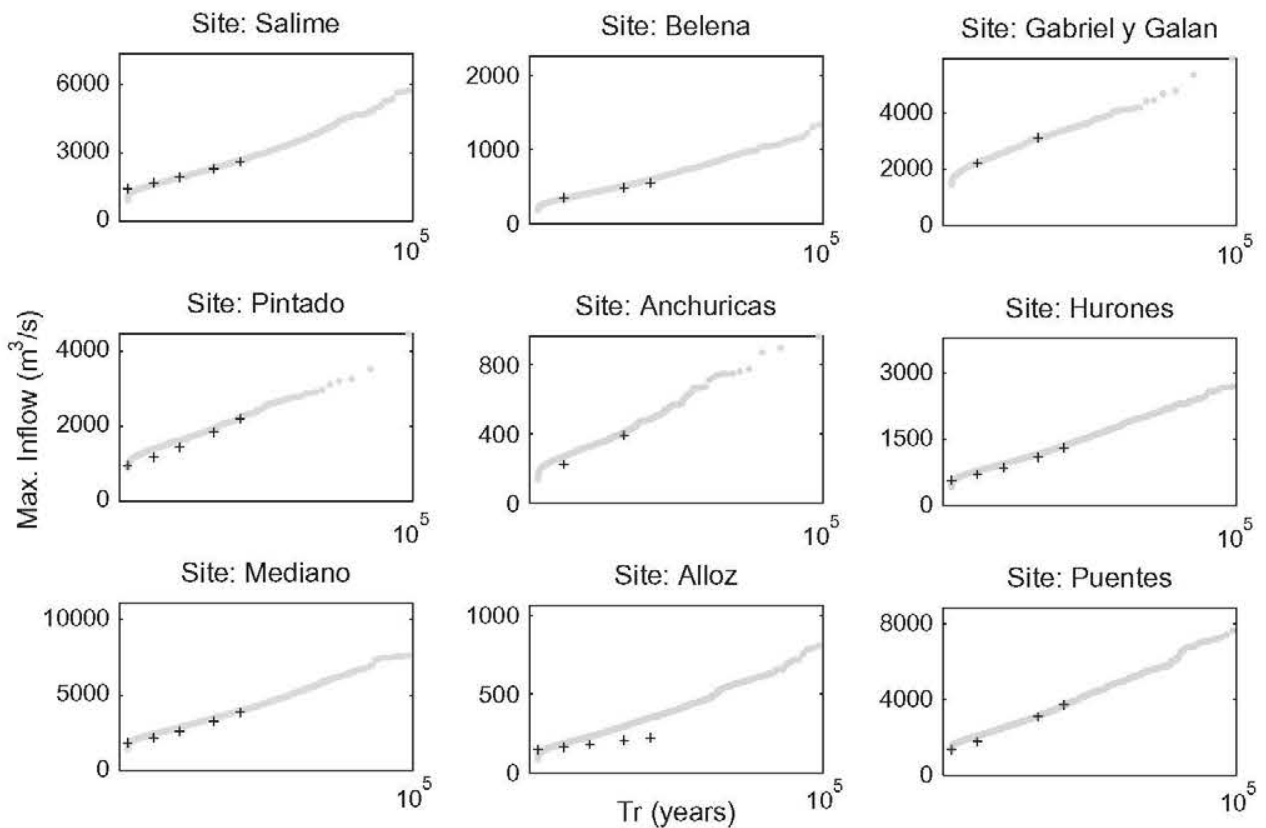

Fig. 7. Comparison of the extremal behaviour of the Qi based on observed data (crosses) and the frequency curve based on the simulated Qi (dots).

Table 2

Stability of the proposed procedure. The results of five simulations with 10,000 repetitions for the Alloz case study (peak flow $\left(\mathrm{m}^{3} / \mathrm{s}\right)$ and volume $\left(\mathrm{h} \mathrm{m}^{3}\right)$ of the inflow hydrographs for different Tr values).

\begin{tabular}{lccccc}
\hline Simulation No. & \multicolumn{5}{l}{ Return period (years) } \\
\cline { 2 - 6 } & 100 & 1000 & 5000 & 7000 & 10,000 \\
\hline Peak flow $\left(\mathrm{m}^{3} / \mathrm{s}\right)$ & 187 & 346 & 491 & 520 & 550 \\
1 & 188 & 352 & 480 & 534 & 564 \\
2 & 187 & 346 & 491 & 522 & 551 \\
3 & 187 & 346 & 491 & 520 & 549 \\
4 & 188 & 353 & 478 & 533 & 564 \\
5 & & & & & \\
Flood volume $\left(\mathrm{h} \mathrm{m}^{3}\right)$ & 5.6 & 10.8 & 15.1 & 16.0 & 16.7 \\
1 & 5.7 & 10.7 & 15.1 & 15.6 & 16.5 \\
2 & 5.7 & 10.5 & 15.1 & 16.0 & 16.7 \\
3 & 5.7 & 10.5 & 15.1 & 16.0 & 16.7 \\
4 & 5.7 & 10.7 & 15.1 & 15.6 & 16.5 \\
5 & & & & & \\
\hline
\end{tabular}

fitted with linear, sigmoidal, exponential and polynomial functions and combinations thereof.

\section{Results}

The reservoir inflow hydrographs generated by the model for the study sites show good fits with the measured data, demonstrating that the maximum flows corresponding to this sample of modelled hydrographs possess extremal behaviour similar to those of the maximum flows obtained from the observed data. An example of nine calibration sites is presented in Fig. 7. The verification of the stability of the results based on the case study of Alloz showed variations in Qi of less than $2.7 \%$ for all the Trs analysed and variations in $\mathrm{Vi}$ of less than $1.2 \%$ (Table 2). In the comparisons of the Qi and $V i$ frequency curves defined with different sample sizes, stability was observed in the results for both Qi and Vi for samples with 5000 and higher number of events, whereas instability was observed for samples with 1000 and 2000 events. (Table 3).

The relationship between Qi and Qo in the 93 studied reservoir and dam configurations showed a linear behaviour (Fig. 8). The coefficient of determination $\left(R^{2}\right)$ was greater than 0.94 for $50 \%$ of
Table 3

Sensitivity of the proposed procedure. The effect of the number of events simulated in the results for the Alloz case study (peak flow $\left(\mathrm{m}^{3} / \mathrm{s}\right)$ and volume $\left(\mathrm{h} \mathrm{m}^{3}\right)$ of the inflow hydrograph for different $\operatorname{Tr}$ values).

\begin{tabular}{llllll}
\hline No. of flood events & \multicolumn{6}{l}{ Return period (years) } \\
\cline { 2 - 6 } & 100 & 1000 & 5000 & 7000 & 10,000 \\
\hline Peak flow $\left(\mathrm{m}^{3} / \mathrm{s}\right)$ & 185 & 366 & 538 & 556 & 593 \\
1000 & 189 & 349 & 475 & 505 & 547 \\
2000 & 189 & 353 & 487 & 525 & 559 \\
5000 & 186 & 346 & 495 & 528 & 555 \\
7000 & 187 & 349 & 486 & 526 & 556 \\
10,000 & & & & & \\
Flood volume $\left(\mathrm{h} \mathrm{m}^{3}\right)$ & 5.6 & 11.0 & 15.9 & 16.6 & 19.4 \\
1000 & 5.7 & 10.6 & 14.7 & 16.2 & 16.5 \\
2000 & 5.6 & 10.9 & 15.4 & 16.1 & 16.8 \\
5000 & 5.7 & 10.5 & 15.2 & 16.1 & 16.8 \\
7000 & 5.7 & 10.7 & 15.1 & 15.8 & 16.7 \\
10,000 & & & & & \\
\hline
\end{tabular}

the cases analysed; $R^{2} \geqslant 0.8$ for $85 \%$, and $R^{2} \geqslant 0.70$ for $100 \%$ of the cases (Fig. 9). Furthermore, the value of $Q y$ varied between -0.025 and 0.012 ( mean $=-0.006$ and median $=-0.004$ ), showing that the fitted lines passed close to the origin in all the cases analysed (Fig. 10)

An example of nine configurations of the relationship between $\mathrm{Qi}$ and RRC for floods simulated with $\mathrm{Qi}$ ranging between $F 1$ and F4 is presented in Fig. 11. In all cases the RRC values remained almost constant in spite of important variations of Qi values. Fig. 12 shows, for each configuration analysed ( $x$-axis), the RRC values ( $y$ axis) for floods of different magnitudes $(F 1-F 4)$. For a better understanding, the configurations were plotted according to ranked (from the lowest to the highest) RRC values. The RRC values between 0 and 0.6 displayed a variation of less than $11.5 \%$. For RRC values greater than 0.6 this variations were less than $5.4 \%$. The average observed behaviour of the relationship between the RRC and the AC coefficient (for F1-F4 floods) is represented by the following analytical expression by the following equation:

$\mathrm{AC}=\frac{-2.60 R R C^{2}+1.81 \mathrm{RRC}+0.75}{R R C^{2}+1.66 \mathrm{RRC}+0.76}$ 
Site: Salime (1)

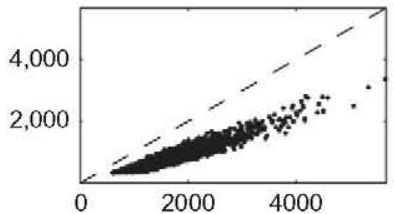

Site: Pintado (4)

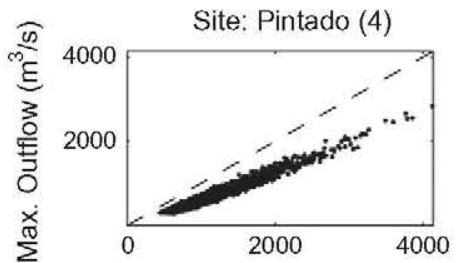

Site: Mediano (7)

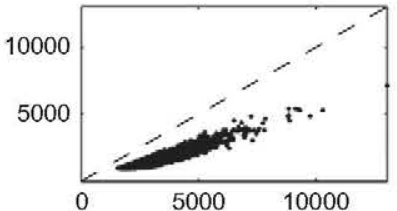

Site: Belena (2)

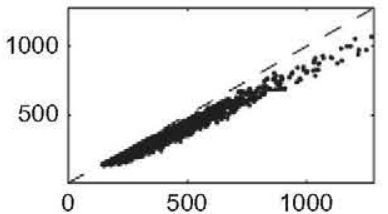

Site: Anchuricas (5)

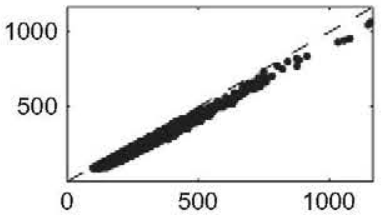

Site: Alloz (8)

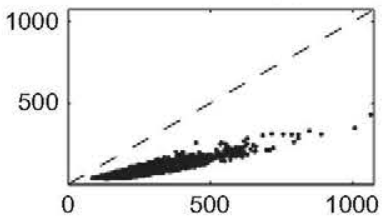

Max. Inflow $\left(\mathrm{m}^{3} / \mathrm{s}\right)$
Site: Gabriel y Galan (3)

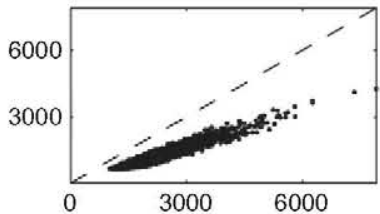

Site: Hurones (6)

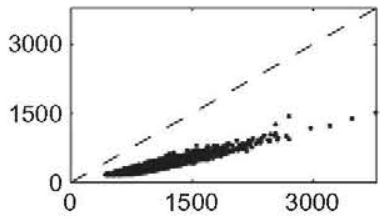

Site: Puentes (9)

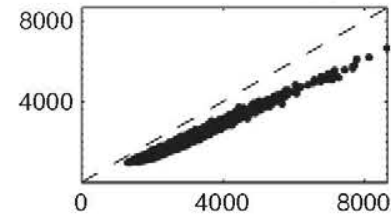

Fig. 8. The maximum reservoir inflow (Qi) vs. the maximum outflow by the dam (Qo) for nine selected configurations.

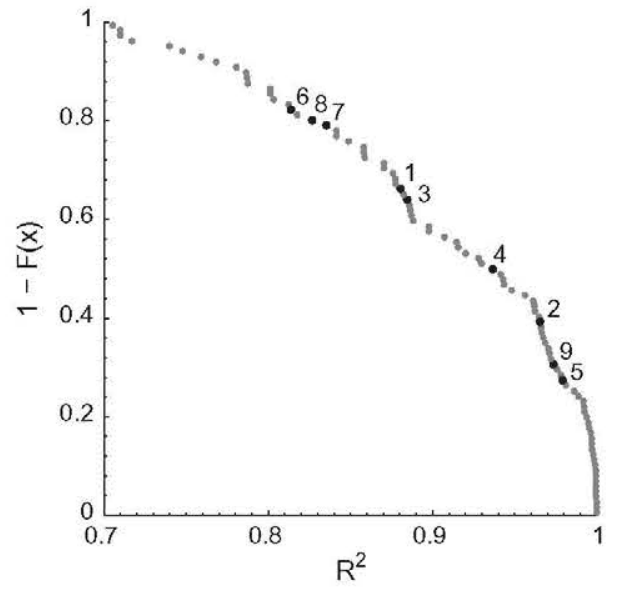

Fig. 9. The linear goodness of fit for the relationship between the maximum reservoir inflow (Qi) and the maximum outflow by the dam (QO). The $x$-axis represents the coefficient of determination $\left(R^{2}\right)$. The $y$-axis represents the probability of exceeding $R^{2}$. The points represent each one of the 93 configurations. The ones highlighted and the numbered represent the cases presented in Fig. 8.

The RMSE value is 0.036 ; with $R R C=0, A C=0.99$ and for $\mathrm{RRC}=1, \mathrm{AC}=-0.01$. Furthermore, the $90 \%$ confidence interval bands show moderate amplitudes (Fig. 13).

\section{Discussion}

Although numerous studies have estimated the frequency laws for Qi using probabilistic approaches, due to the complexity of the physical processes involved and the computational effort expense required for full modelling, the majority have been limited to low return periods (1-100 years) or small watersheds (1$100 \mathrm{~km}^{2}$ ) (Arnaud and Lavabre, 2002; Loukas, 2002; Aronica and Candela, 2007). Various authors have suggested a minimum sample size necessary with ratios, for example, between the maximum $\operatorname{Tr}$ of the sample and the maximum $\operatorname{Tr}$ to be estimated, of no less

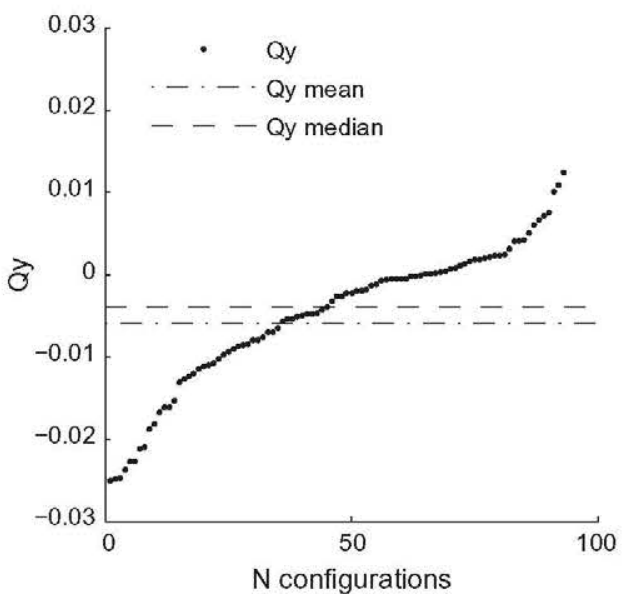

Fig. 10. The evaluation of the independent variable for the fitted lines. The configuration number analysed is indicated on the $x$-axis. $Q y$ is represented on the $y$-axis, ordered from low to high. The dots represent each of the 93 configurations for floods of magnitude $F 2$. The line and the point indicate mean values and the dashed line indicates the median value.

than 10 or 20 (e.g., Loukas, 2002; Blazkova and Beven, 2004). This study centred on floods with high $\mathrm{Tr}$ (between 500 and 10,000 years) and so would have been compromised by computational limitations (Bocchiola and Rosso, 2009) with the prior approach, as it would require the performance of $100,000-200,000$ simulations to obtain representative samples for the upper range.

To address this shortcoming, a simple random selection method was proposed that allows hydrographs to be obtained for various temporal distributions with maximum $\operatorname{Tr}$ values on the order of 500,000 years and only 10,000 simulations (or, equivalently, with a ratio of 50 for the maximum $\mathrm{Tr}$ of the sample and the maximum $\operatorname{Tr}$ to be estimated), which implies a savings in computation time by a factor of $20-50$ with respect to a simple selection including the entire $\operatorname{Tr}$ range. The $\operatorname{Tr}$ ratio of 50 ensures that, although a rain event with a particular $\operatorname{Tr}$ will not necessarily generate a flood with 

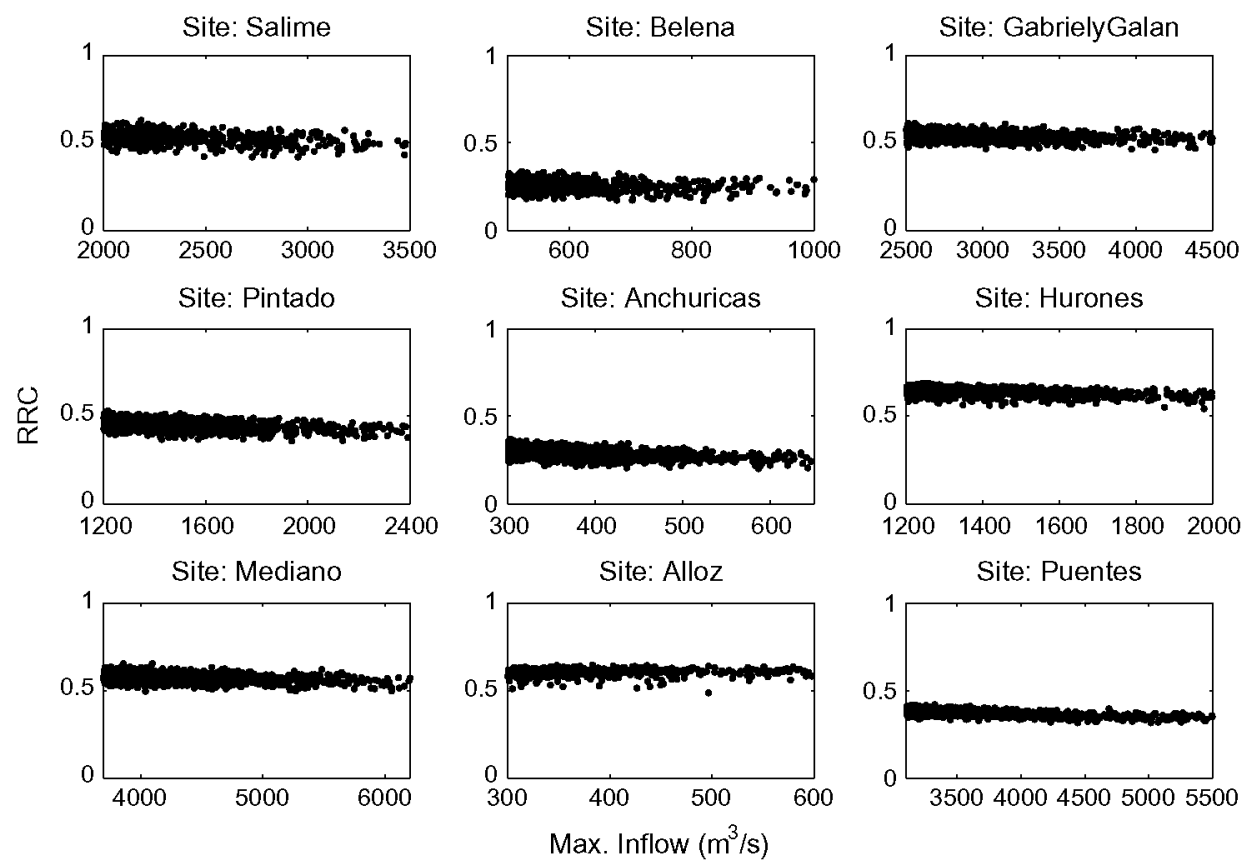

Fig. 11. The maximum reservoir inflow (Qi) vs. the RRC coefficient for nine selected configurations.

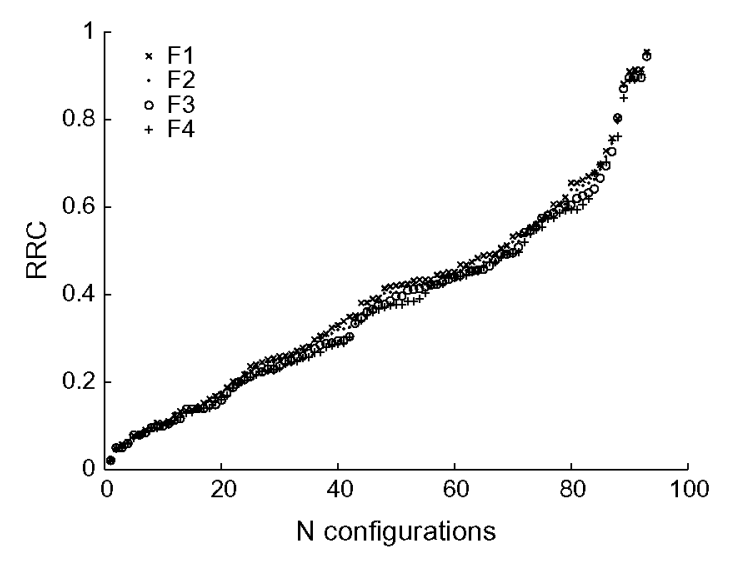

Fig. 12. Evaluation of the Reservoir Routing Coefficient (RRC) given floods of different magnitudes. The $x$-axis indicates the configuration number analysed. The $y$-axis represents the RRC, ordered from low to high. The symbols represent floods of different magnitudes: $\times, F 1$; dots, $F 2$; circles, $F 3$; and crosses, $F 4$.

a maximum flow of the same $\mathrm{Tr}$, hydrographs will indeed be obtained with high $\operatorname{Tr}$ values that are representative of extreme hydrological forcing (Alfieri et al., 2008; Viglione and Blöschl, 2009). The analysis of the stability and sensitivity of the results to the selected sample size showed acceptable values considering the uncertainty associated with the estimation of floods with such high Tr values. The proposed procedure is capable of reproducing a frequency law for Qi similar to that calculated based on a rigorous procedure for the stochastic generation of storms (i.e., MBLM).

With respect to design conditions, under the assumptions used in this study, the Qo/Qi ratio remains stable when modelling flood events with great variability in magnitude and temporal distribution. Additionally, noting that the proposed linear fit of Qo vs. Qi passes close to the coordinate origin, we can estimate the overall behaviour of the flood abatement effect of the reservoir with a small, known (or simulated) number of representative floods and without the need to know the $\operatorname{Tr}$ associated with these floods. The abatement effect for the entire range of design flows would

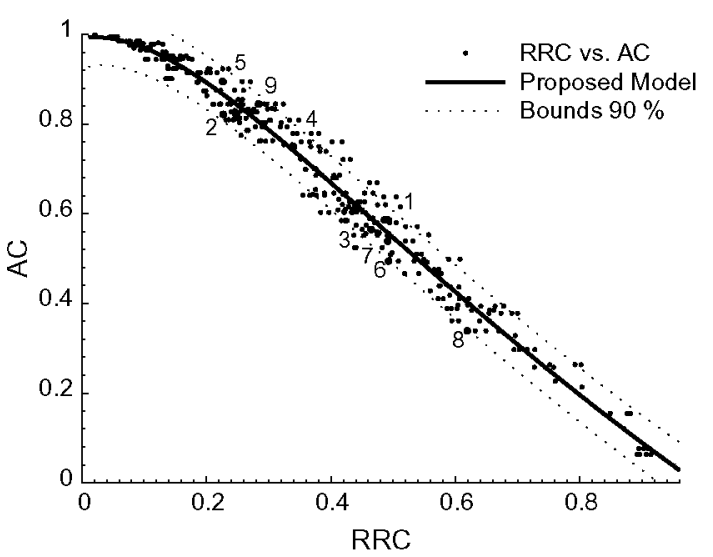

Fig. 13. The Reservoir Routing Coefficient (RRC) plotted against the Attenuation Coefficient $(\mathrm{AC})$, showing the average behaviour considering flood magnitudes from $F 1$ to $F 4$. The solid line represents the fitted line, and the dotted lines represent confidence intervals of $90 \%$. The ones highlighted and the numbered represent the cases presented in Fig. 8.

thus be a line passing through the coordinate origin with a slope reflecting the average $\mathrm{Q} / \mathrm{Qi}$ ratio of the selected floods (Fig. 14). The above procedure allows for a simple preliminary evaluation of the flood abatement capacity of a fixed-crest dam under extreme hydrological forcing.

The adjustment function for the ratio between the RRC and the AC (Fig. 13) constitutes a simple model that allows for the estimation of the flood abatement effect of the reservoirs based on generally available information (e.g., the volume of reservoir available for flood abatement, the maximum reservoir inflow, the volume of the inflow hydrograph and the maximum allowable flow downstream from the dam). The physicality of the model is reflected in the fact that as the maximum abatement volume tends to 0 (i.e., RRC decreases), AC approaches $1(\mathrm{Qi} \approx \mathrm{Q} 0)$, whereas if the available volume for abatement is similar to Vi (i.e., RRC tends toward 1 ), then $A C$ approaches 0 (as the Qo values are very small). It is normal for dam discharge to be limited by downstream considerations of 


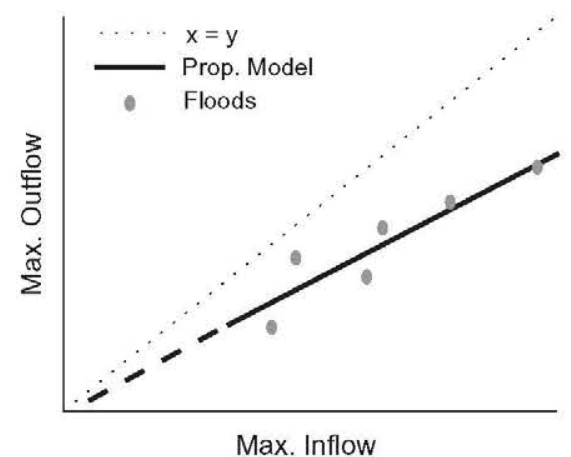

Fig. 14. General scheme representing a simple model for the estimation of the attenuation effect of peak inflows in dams with FC spillways. The dots indicate the Qo/Qi ratio of the simulated or known hydrographs. The solid line represents the fitted line that passes through the origin.

flooding and social, environmental and other conditions. Based on the proposed fitting, with an estimation of $\mathrm{Qi}$ and $\mathrm{Vi}$ at a study site, it is possible to estimate the required abatement volume in a reservoir satisfying such restrictions on Qo. The estimation of $\mathrm{Qi}$ and Vi may be performed based on observed or simulated data (either with specific hydrologic studies or using the procedure described in this work). The estimation does not require to account the $\mathrm{Tr}$ associated with these values, given the slight dependence of RRC with respect to the $\mathrm{Tr}$ of the floods shown in our results. Another direct application is the estimation of Qo based on the knowledge of $\mathrm{Vi}, \mathrm{Qi}$ and the maximum available abatement volume (based on construction limitations, the topography of the area or flooding considerations upstream of the dam).

A simplified formulation of the problem of reservoir flood abatement estimation used by various authors, generally applied to urban hydrology to obtain the ratio between $\mathrm{Qi}$ and Qo and between $\mathrm{Vi}$ and the abatement volume, is to assume triangular hydrographs for both the reservoir inflow and the dam outflow (Quader and Guo, 2006; Guo and Zhuge, 2008; Bacchi et al., 2008). Calculating the volume of the inflow hydrograph, the maximum available volume for abatement and the RRC and AC coefficients yields by the following equation:

$\mathrm{RRC}_{i}=1-\mathrm{AC}_{i}$

where $i$ indicates the magnitude of the flood being analysed. The difference between this model and the relationship obtained in this study (Fig. 13) lies fundamentally in the variability of the shapes of the hyetographs and inflow and output hydrographs being considered. Furthermore, the results obtained in this study agree with the studies developed by Hager and Sinniger (1985) and Horn (1987), in which an effect was noted between the shape of the inflow hydrographs and the flood abatement produced in the reservoir.

Based on the strong correlation observed between Qi and Qo for the entire range of hydrographs analysed, the proposed procedure allows the frequency law for Qo to be estimated based on the frequency law for Qi. That is, given a frequency law for Qi obtained by any method (e.g., based on the statistical analysis of observed data or hydrometeorological models), the frequency law for Qo can obtained by multiplying this by the AC coefficient for the case under study (see Fig. 15).

\section{Validation of the procedure and model: applications}

The validation and application of the proposed procedure and model was performed for four study sites, comprising 12 dam and reservoir configurations (in addition to those used for the

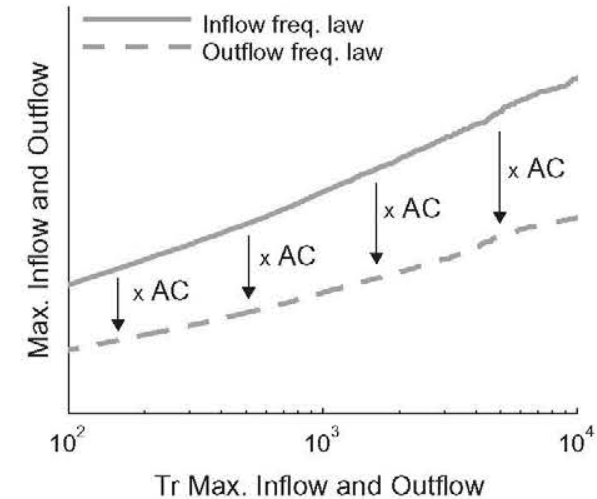

Fig. 15. General scheme representing the estimation of the frequency law for Qo based on the frequency law for Qi by applying the Attenuation Coefficient (AC) as a multiplier.

calibration and development of the procedure and model). First, the proposed linear model was validated, as illustrated in Fig. 14, to correlate Qi and Qo (Table 4). For each configuration (Table 4, col. 1), (a) six hydrographs were routed through the reservoir, covering the range of magnitudes defined between $F 1$ and $F 4$; (b) a linear fitting was performed for the relationship between the Qi and Qo values obtained with the six hydrographs (SM), and the $R^{2}$ was calculated (Table 4, cols. 2 and 3); (c) the Qo values were determined for 10,000 simulations by applying the obtained fit (Qo_SM), and the mean normalised difference was calculated with the Qo obtained by performing the abatement according to the complete model (Qo_FM; uses the Storage Indication Method (SCS, 1972) (Table 4, col. 4); (d) similarly, a linear fitting was performed for the 10,000 simulations by applying the complete model (adj_FM), the $R^{2}$ was calculated (Table 4, cols. 5-7), the Qo values were calculated with the new fit that was obtained (Qo_adj_FM), and the mean normalised difference was found with the Qo_FM (Table 4, col. 8); finally, (e) the difference was found between the slopes of the fitted lines for SM and adj_FM, and the mean normalised difference was calculated between Qo_SM and Qo_adj_FM (Table 4, cols. 9 and 10). A mean value of $7.2 \%$ was obtained for the mean normalised differences between Qo_SM and Qo_FM for the twelve configurations (with 10,000 simulations/configuration). The greatest differences occurred in configurations with means floods abatement greater than $40 \%$ and which corresponded to $F 1$ floods or less. Similarly, an average value of $5.9 \%$ was obtained for the difference between Qo_adj_FM and Qo_FM. Although the calculations for Qo_SM and Qo_adj_FM were based on fits with 6 and 10,000 floods, respectively, they yielded similar values for the results obtained (Table 4). Furthermore, the slopes of the fitted lines calculated for 6 and 10,000 floods displayed differences of less than $10 \%$ in more than $90 \%$ of the configurations. Finally, the average of the mean normalised differences between Qo_adj_FM and Qo_SM was 3.7\%. This demonstrates the good behaviour of the proposed model in the 12 configurations and 10,000 floods/configuration that were studied.

Next, the model presented in Fig. 13 and given by Eq. (5) was validated. This model establishes a relationship between the RRC and the AC (Table 5). In each configuration (Table 5, cols. 1-3), the RRC was obtained based on the known behaviour of a design flood (Table 5, cols. 4 and 5 ; in this case, F2 floods were considered), and the AC was obtained by applying Eq. (5) (Table 5, cols. 6 and 7). To verify the results, the Qo were calculated for 10,000 simulations by multiplying the Qi by the AC (Qo_SM2), and a linear fit was constructed for Qo_SM2 vs. Qo_FM (Table 5, cols. 8-10). In addition, the mean normalised difference between Qo_SM2 and Qo_FM was obtained (Table 5, col. 11). The linear fit was good, with 
Table 4

Validation of the proposed procedure for determining the ratio between Qi and Qo.

\begin{tabular}{|c|c|c|c|c|c|c|c|c|c|}
\hline \multicolumn{4}{|c|}{ Linear fit (SM) } & \multicolumn{6}{|c|}{ Linear fit (adj_FM) } \\
\hline (1) & $(2)$ & (3) & (4) & (5) & (6) & (7) & $(8)$ & (9) & $(10)$ \\
\hline Site & Slope (-) & $R^{2}(-)$ & Diff.1 $(\%)$ & Slope (-) & Qy $(-)$ & $R^{2}(-)$ & Diff.2 $(\%)$ & Sl_SM/Sl_FM (-) & Diff.3 $(\%)$ \\
\hline Escalona1 & 0.87 & 0.99 & 5.94 & 0.80 & -0.01 & 0.96 & 4.85 & 1.09 & 3.53 \\
\hline Escalona2 & 0.98 & 1.00 & 0.61 & 0.98 & 0.00 & 1.00 & 0.57 & 1.01 & 0.20 \\
\hline Escalona3 & 0.97 & 1.00 & 2.84 & 0.93 & -0.01 & 0.99 & 2.35 & 1.05 & 1.54 \\
\hline Casoyo1 & 0.86 & 1.00 & 7.44 & 0.87 & -0.01 & 0.97 & 5.50 & 0.99 & 6.24 \\
\hline Casoyo 2 & 0.63 & 0.97 & 15.99 & 0.63 & -0.02 & 0.89 & 10.85 & 1.00 & 13.06 \\
\hline Casoyo3 & 0.90 & 1.00 & 5.21 & 0.91 & -0.01 & 0.99 & 3.56 & 0.98 & 4.64 \\
\hline Itoiz1 & 0.52 & 0.95 & 13.78 & 0.45 & -0.01 & 0.83 & 12.03 & 1.15 & 3.32 \\
\hline Itoiz2 & 0.87 & 0.99 & 5.79 & 0.83 & 0.00 & 0.96 & 5.09 & 1.04 & 3.05 \\
\hline Itoiz3 & 0.93 & 1.00 & 2.58 & 0.94 & 0.00 & 1.00 & 1.52 & 0.98 & 2.36 \\
\hline Las Torcas 1 & 0.83 & 0.99 & 4.02 & 0.84 & 0.01 & 0.98 & 3.57 & 0.99 & 2.41 \\
\hline Las Torcas2 & 0.58 & 0.94 & 9.72 & 0.56 & -0.01 & 0.88 & 9.45 & 1.04 & 1.28 \\
\hline \multirow[t]{2}{*}{ Las Torcas 3} & 0.44 & 0.91 & 12.40 & 0.41 & -0.02 & 0.84 & 11.68 & 1.06 & 3.30 \\
\hline & & Mean: & 7.2 & & Mean: & 5.9 & & Mean: & 33.7 \\
\hline
\end{tabular}

Table 5

Validation of the proposed model, establishing a relationship between the RRC and AC coefficients.

\begin{tabular}{|c|c|c|c|c|c|c|c|c|c|c|}
\hline \multicolumn{5}{|l|}{ Input data } & \multicolumn{2}{|c|}{ Simple Model } & \multicolumn{4}{|c|}{ Linear fit (Qo_SM2 vs.Qo_FM) } \\
\hline (1) & $(2)$ & (3) & (4) & (5) & $(6)$ & (7) & $(8)$ & (9) & $(10)$ & (11) \\
\hline Site & FC length (m) & VMNL $\left(\mathrm{h} \mathrm{m}^{3}\right)$ & $\operatorname{Vi}\left(h \mathrm{~m}^{3}\right)$ & $\mathrm{FCV}\left(\mathrm{h} \mathrm{m}^{3}\right)$ & RRC (-) & $\mathrm{AC}(-)$ & Slope $(-)$ & Qy (-) & $R^{2}(-)$ & Diff. $4(\%)$ \\
\hline Escalona1 & 54 & 108 & 96.1 & 28.5 & 0.30 & 0.79 & 0.95 & 0.02 & 0.96 & 6.38 \\
\hline Escalona2 & 54 & 10 & 96.1 & 7.6 & 0.08 & 0.98 & 1.00 & 0.00 & 0.99 & 0.58 \\
\hline Escalona3 & 132 & 108 & 96.1 & 16.8 & 0.18 & 0.91 & 0.98 & 0.01 & 0.99 & 2.40 \\
\hline Casoyo1 & 40 & 30 & 10.7 & 2.9 & 0.27 & 0.82 & 0.91 & 0.02 & 0.97 & 5.31 \\
\hline Casoyo 2 & 12 & 30 & 10.7 & 5.1 & 0.47 & 0.58 & 0.81 & 0.03 & 0.89 & 10.58 \\
\hline Casoyo 3 & 12 & 5 & 10.7 & 2.2 & 0.21 & 0.88 & 0.95 & 0.01 & 0.99 & 3.57 \\
\hline Itoiz1 & 50 & 418 & 50.8 & 29.5 & 0.58 & 0.45 & 0.82 & 0.03 & 0.83 & 16.10 \\
\hline Itoiz2 & 50 & 65 & 50.8 & 13.0 & 0.26 & 0.83 & 0.97 & 0.00 & 0.96 & 5.49 \\
\hline Itoiz3 & 24 & 6.5 & 50.8 & 5.8 & 0.11 & 0.96 & 1.01 & 0.00 & 0.99 & 1.78 \\
\hline Las Torcas 1 & 10 & 7 & 35.5 & 8.8 & 0.25 & 0.84 & 0.98 & 0.00 & 0.98 & 4.70 \\
\hline Las Torcas2 & 10 & 48 & 35.5 & 18.7 & 0.53 & 0.51 & 0.81 & 0.03 & 0.88 & 9.18 \\
\hline \multirow[t]{2}{*}{ Las Torcas 3} & 10 & 100 & 35.5 & 22.9 & 0.65 & 0.37 & 0.75 & 0.04 & 0.85 & 11.16 \\
\hline & & & & & & & & & Mean: & 6.4 \\
\hline
\end{tabular}

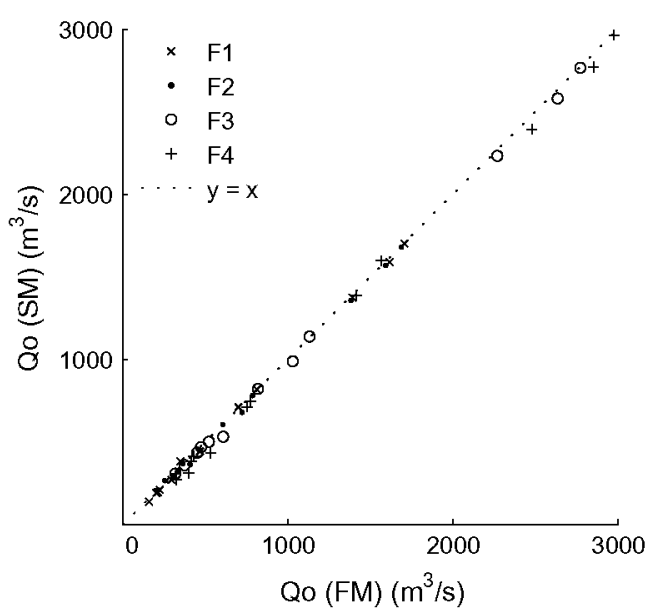

Fig. 16. Validation of the frequency law for Qo obtained by multiplying the frequency law for Qi by the $A C$, based on a comparison of the results for the Qo values for $F 1-F 4$ floods obtained by applying the proposed model (Eq. (5)) and the FM to 12 dam and reservoir configurations.

slopes greater than 0.8 in more than $90 \%$ of the configurations analysed and $R^{2}$ values greater than 0.8 for all configurations (averaging 0.94). Furthermore, the average of the mean normalised difference between Qo_SM2 and Qo_FM was 6.4\%. The above results validate the proposed model in that, based on the knowledge of the behaviour of one design flood, it is possible to estimate the slope of the fitted line for the relationship between Qi and Qo for the entire range of floods (the $A C$ ).

Finally, we validated the procedure for estimating the frequency law for Qo based on the frequency law for Qi, multiplying the latter by AC (Fig. 15). For each configuration, the Qo was calculated for floods with magnitudes of $F 1-F 4$ using the AC calculated in the previous validation; the corresponding Qo_FM were calculated, and the results were compared (Fig. 16). The observed fit was excellent for all the configurations analysed (here, $y=x$ indicates a perfect fit), thus validating the frequency law obtained for Qo based on that for Qi using the procedure proposed in this study.

\section{Conclusions}

We employed probabilistic analysis techniques with the objective of evaluating the flood abatement effects of dams with FC spillways at various sites (in watersheds with areas between 150 and $2000 \mathrm{~km}^{2}$ ) and floods with high $\operatorname{Tr}$ values (on the order of $50-500,000$ years). We designed an automated calculation tool that integrates a series of models representing the different physical processes involved. This tool was developed in a Monte Carlo simulation environment and generates a set of hydrographs as an approximation of the stochastic hydrological forcing of a dam and the dam's response to this forcing at a low computational cost. This was applied to 21 sites uniformly distributed throughout continental Spain, with 105 FC dam configurations, and approximately $6,000,000$ simulations were performed. In all of the studied cases, we obtained a strong linear correlation between Qi and Qo, which 
allowed for the characterisation of the flood abatement behaviour of the reservoirs. This linear function allows us to estimate the overall behaviour of the flood abatement effect of a reservoir for design flows based on a limited number of hydrographs (either measured or simulated) and without the need to know the Tr associated with these hydrographs.

We defined a set of dimensionless coefficients (the AC and the RRC) that allows for the characterisation of the response of a dam to a stochastic hydrological forcing and formulated an analytical expression that establishes a relationship between these coefficients. In the above analysis, a number of important practical considerations emerges, such as the probability that the discharge flow may exceed the threshold associated with damage to a particular downstream entity, the estimation of the attenuation of $\mathrm{Qi}$ based on the preliminary knowledge of a reduced number of hydrographs (either measured or simulated) and the estimation of the approximate frequency law for Qo from the frequency law for $\mathrm{Qi}$, among others. Furthermore, the proposed procedure and model were evaluated, with good results, by applying them to several different dam and reservoir configurations and to a wide range of stochastic hydrological forcing.

In summary, using the procedure presented herein, based on the proposed adjustment function and on generally available information, it is possible to perform a simple first evaluation of the flood abatement capacity of a dam faced with extreme hydrological forcing, which can guide the designer in the preliminary design phase or the evaluation of the hydrological safety of a dam.

\section{Acknowledgements}

The study was made possible by the funds from CEDEX (the Public Works Studies and Experimentation Centre, Ministry of Development, Spain) in the framework of the project "Technical assistance for the analysis of methodologies to improve flood hydrograph estimation", the ARCO Project (200800050084350) "Vulnerability, impacts and adaptation to climate change: agriculture, water resources and coastal management", funded by the Spanish Ministry of Environment, Rural and Marine Affairs, and MODEX Project (CGL2011-22868) "Physically-based modelling for characterisation of extreme hydrologic response under a probabilistic approach. Application to dam safety analysis and optimization of reservoir operation during floods", funded by the Spanish Ministry of Science and Innovation. We also thank Antonio Jiménez for his comments and suggestions during the development of this study, to Miguel Angel Campo for his collaboration in the stochastic analysis of rain events, and Adriadna Chávez for his support with the illustrations.

\section{References}

Adams, B., Howard, C.D., 1986. Design storm pathology. Can. Water Resour. J. 11 (3), $49-55$.

Adams, B., Papa, F., 2000. Urban stormwater Management Planning with Analytical Probabilistic Models. John Wiley \& Sons, Inc., New York.

Akan, A.O., 1989. Detention pond sizing for multiple return periods. J. Hydraul. Eng.ASCE. 115 (5), 650-664.

Alfieri, L., Laio, F., Claps, P., 2008. A simulation experiment for optimal design hyetograph selection. Hydrol. Process. 22 (6), 813-820.

Arnaud, P., Lavabre J., 2002. Coupled rainfall model and discharge model for flood frequency estimation. Water Resour. Res. 38 (6), 11-1-11-11.

Arnaud, P., Fine, J., Lavabre, J., 2007. An hourly rainfall generation model applicable to all types of climate. Atmos. Res. 85, 230-242.

Aronica, G., Candela, A., 2007. Derivation of flood frequency curves in poorly gauged Mediterranean catchments using a simple stochastic hydrological rainfallrunoff model. J. Hydrol. 347, 132-142.

Bacchi, B., Balistrocchi, M., Grossi, G., 2008. Proposal of a semi-probabilistic approach for storage facility design. Urban Water J. 5 (3), 195-208.

Barnolas, M., Llasat, M.C., 2007. A flood geodatabase and its climatological applications: the case of Catalonia for the last century. Nat. Hazards Earth Syst. Sci. $7,271-281$.
Blazkova, S., Beven, K., 2004. Flood frequency estimation by continuous simulation of subcatchment rainfalls and discharges with the aim of improving dam safety assessment in a large basin in the Czech Republic. J. Hydrol. $292(1-4), 153-172$.

Blazkova, S., Beven, K., 2009. A limits of acceptability approach to model evaluation and uncertainty estimation in flood frequency estimation by continuous simulation: Skalka catchment, Czech Republic. Water Resour. Res. 45, W00B16.

Bocchiola, D., Rosso, R., 2006. The use of scale recursive estimation for short term quantitative precipitation forecast. Phys. Chem. Earth. 31, 1228-1239.

Bocchiola, D., Rosso, R., 2009. Use of a derived distribution approach for flood prediction in poorly gauged basins: a case study in Italy. Adv. Water Resour. 32, 1284-1296.

Boughton, W., Droop, O., 2003. Continuous simulation for design flood estimation a review. Environ. Modell. Softw. 18, 309-318.

Bras, R., Rodríguez Iturbe, I., 1993. Random Functions and Hydrology. Dover Publications, USA, 559.

Burton, A., Kilsby, C., Fowler, H., Cowpertwait, P., O'Connell, P., 2008. RainSim: a spatial-temporal stochastic rainfall modelling system. Environ. Modell. Softw. 23 (12), 1356-1369.

Burton, A., Fowler, H.J., Kilsby, C.G., O'Connell, P.E., 2010. A stochastic model for the spatial-temporal simulation of nonhomogeneous rainfall occurrence and amounts. Water Resour. Res. 46, W11501.

Cameron, D., Beven, K., Naden, P., 2000. Flood frequency estimation by continuous simulation under climate change (with uncertainty). Hydrol. Earth Syst. Sci. 4 (3), 393-405.

CEDEX, 2011. Mapa de caudales máximos. <http://www.magrama.es/es/agua/ temas/gestion-de-los-riesgos-de-inundacion/memoria_tecnica_v2.0_tcm7162773.pdf>

Cernesson, F., Lavabre, J., Masson, J., 1996. Stochastic model for generating hourly hyetographs. Atmos. Res. $42(1-4), 149-161$.

Chow, V.T., Maidment, D., Mays, L., 1988. Applied Hydrology. Mc Graw Hill, New York, 572.

Cui, Z., Vieux, B.E., Neeman, H., Moreda, F., 2005. Parallelisation of a distributed hydrologic model. Int. J. Comput. Appl. T. 22 (1), 42-52.

De Michele, C., Salvadori, G., 2002. On the derived flood frequency distribution: analytical formulation and the influence of antecedent soil moisture condition. J. Hydrol. 262, 245-258.

Etoh, T., Murota, A., Nakanishi, M., 1986. SQRT-exponential type distribution of maximum. In: Shing, V.P. (Ed.), Proceedings of the International Symposium on Flood Frequency and Risk Analyses, 14-17 May, 1986. Louisiana State University, Reidel Pub. Com., USA, pp. 253-264.

Graber, S.D., 2009. Generalized numerical solution for detention basin design. J. Irrig. Drainage Eng.-ASCE 135 (4), 487-492.

Guo, Y., 2001. Hydrological design of urban flood control detention ponds. J. Hydrol. Eng. 6(6), 472-479.

Guo, Y., Zhuge, Z., 2008. Analytical probabilistic flood routing form urban stormwater management purposes. Can. J. Civil Eng. 35, 487-499.

Hager, W.H., Sinniger, R., 1985. Flood storage in reservoirs. J. Irrig. Drainage Eng.ASCE 111 (1), 76-85.

Hong, Y.M., 2008. Graphical estimation of detention pond volume for rainfall of short duration. J. Hydro-Environ. Res. 2 (2), 109-117.

Horn, D.R., 1987. Graphic estimation of peak flow reduction in reservoirs. J. Hydraul. Eng.-ASCE 113 (11), 1441-1450.

ICOLD (International Comission on Large Dams), 1995. Dam Failures: Statistical Analysis. ICOLD, Bulletin 99, Paris.

Kollet, S.J., Maxwell, R.M., Woodward, C.S., Smith, S., Vanderborght, J., Vereecken, H., Simmer, C., 2010. Proof of concept of regional scale hydrologic simulations at hydrologic resolutions utilizing massively parallel computing resources. Water Resour. Res. 46, W0421.

Loukas, A., 2002. Flood frequency estimation by a derived distribution procedure. J. Hydrol. 255, 69-89.

Ministerio de Fomento, 1999. Máximas lluvias diarias en la España peninsular Dirección General de Carreteras. Ministerio de Fomento - Centro de publicaciones, Madrid, España.

MARM (Ministerio de Medio Ambiente y Medio Rural y Marino), 2011. <http:// www.sig.marm.es/snczi/visor.html?herramienta=Presas >.

MOPU (Ministerio de Obras Públicas y Urbanismo), 1990. Instrucción de carreteras 5.2-IC "Dreanje Superficial". Dirección General de Carreteras, BOE 123, 23/05/ 1990 , pp. $389-396$.

Ponce, V., 1989. Engineering Hydrology. Principles and Practices. Prentice Hall, New Jersey, USA.

Quader, A., Guo, Y., 2006. Peak discharge estimation using analytical probabilistic and design storm approach. J. Hydrol. Eng. 11 (1), 46-54.

Rahman, A., Weinmann, P.E., Hoang, T.M.T., Laurenson, E.M., 2002. Monte Carlo simulation of flood frequency curves from rainfall. J. Hydrol. 256, 196-210.

Rebolé, J., Lopez, J., Garcia, A., 2009. Caracterización estadística de las variables en el proceso secuencial de lluvia. Revista Ingeniería del Agua 16 (2), 81-94.

Rodriguez-Iturbe, I., Valdés, J., 1979. The geomorphologic structure of hydrologic response. Water Resour. Res. 15 (6), 1409-1420.

Salas, L., Fernández, J., 2007. "In-site" regionalization to estimate an intensityduration-frequency law: a solution to scarce spatial data in Spain. Hydrol. Proc. $21,3507-3513$.

Samuel, J.M., Sivapalan, M., 2008. Effects of multiscale rainfall variability on flood frequency: comparative multisite analysis of dominant runoff processes. Water Resour. Res. 44, W09423.

SCS (USDA Soil Conservation Service), 1972. National Engineering Handbook, Section 4: Hydrology. U.S. Department of Agriculture, Washington, DC, USA. 
Serrano-Lombillo, A., Escuder-Bueno, I., Membrillera-Ortuño, M.G., Altarejos-Garcia, L., 2010. Methodology for the calculation of annualized incremental risks in systems of dams. Risk Anal. http://dx.doi.org/10.1111/j.1539-6924.2010. 01547.x.

SPANCOLD (Spanish National Committee on Large Dams), 1997. Guía técnica de seguridad de presas: No. 4. Avenida de Proyecto, SPANCOLD, Madrid, Spain.

Srikanthan, R., McMahon, T., 2001. Stochastic generation of annual, monthly and daily climate data: a review. Hydrol. Earth Syst. Sci. 5 (4), 653-670.
Toth, E., Brath, A., Montanari, A., 2000. Comparison of short-term rainfall prediction models for real-time flood forecasting. J. Hydrol. 239, 132-147.

Viglione, A., Blöschl, G., 2009. On the role of storm duration in the mapping of rainfall to flood return periods. Hydrol. Earth Syst. Sci. 13, 205-216.

Wilks, D., Wilby, R., 1999. The weather generation game: a stochastic weather models. Prog. Phys. Geogr. 23 (3), 329-357.

Zorraquino, C., 2004. The SQRT-ETmax Model. Revista de Obras Publicas 3 (447), 33-37. 